\title{
Job Satisfaction and Burnout among Greek Teachers and Physical Education Teachers: A Comparison in Minority and Public Sector Schools in Thrace
}

\author{
${ }^{1}$ Sotirios Vousiopoulos ${ }^{*},{ }^{1}$ Olga Kouli, ${ }^{1}$ Thomas Kourtessis, ${ }^{1}$ Efstratia Tsitskari, ${ }^{2}$ Dimos \\ Dimoulas \\ ${ }^{1}$ Department of Physical Education and Sport Sciences, Democritus University of Thrace, Komotini, \\ Greece. ${ }^{2}$ School of English, Aristotle University of Thessaloniki, Thessaloniki, Greece.
}

Submitted 28 June 2019; Accepted in final form 15 August 2019.

\begin{abstract}
Background. Job satisfaction has been an issue of intense study interest during the last decades. It could be defined a positive emotional state resulting from the appraisal of one's job situation and is linked to the characteristics and demands of one's work. Also that interest in the concept of job burnout has grown rapidly and the knowledge of burnout has increased considerably. Burnout is defined as a negative experience that is a reaction of people to jobrelated stress. Objectives. The present study seeks to investigate the levels of job satisfaction and burnout in Teachers and Physical Education Teachers of Minority and Public Sector Schools, as well as their relation to demographic characteristics. Methods. The Employee Satisfaction Inventory questionnaire, adapted for the Greek population, was employed to assess job satisfaction. For the measurement of burnout, Maslach Burnout Inventory questionnaire was used, which has also been validated for the Greek population. Questionnaires were picked up by 297 Primary School Teachers and by 142 Physical Education Teachers, who serve at 186 Minority Schools and 253 Public Schools of Thrace. Results. The results of the study revealed a negative relation between job satisfaction and burnout; teachers experience relatively moderate burnout levels, their job satisfaction level is high. The results showed that Physical Education teachers experience higher job satisfaction and lower burnout than Primary school teachers. Finally, concerning school, the type of school affects satisfaction in relation to the factor "job conditions". Conclusion. For the first time, burnout and job satisfaction of teachers in minority schools was studied and the results revealed that when job satisfaction increases, the perceived burnout decreases, where job satisfaction and burnout presented medium to high negative correlation.
\end{abstract}

\section{KEYWORDS: Primary Education, Minority Schools, Physical EducationTeachers, Burnout, Job Satisfaction}

\section{INTRODUCTION}

Job satisfaction has been an issue of intense study interest during the last decades. It could be defined a positive emotional state resulting from the appraisal of one's job situation and is linked to the characteristics and demands of one's work (1-3). As stated by Blandford, the work-related satisfaction can be rendered by helping people, achieving change and improvement, and by promoting students' growth which has important implications for and teachers' behavior at work, on their desire to continue at work and their involvement in the job (4). It could be claimed that interest in the concept of job burnout has grown rapidly and the knowledge of burnout has

*. Corresponding Author:

Sotirios Vousiopoulos, $\mathrm{PhD}$

E-mail: svousiop@phyed.duth.gr 
increased considerably. 'Burnout' refers to a cluster of physical, emotional and interactional symptoms, including the emotional exhaustion, a sense of lacking personal accomplishment and depersonalization of clients (5). Maslach and Jackson state that burnout comprises three factors: 'emotional exhaustion', which is described as feelings of being emotionally overextended, 'reduced personal accomplishment', which is experienced by teachers as decreased feelings of achievement and 'depersonalization' which is the development of negative feelings and attitudes about the job (5). Furthermore, for Pines and Aronson, burnout is a state of physical, emotional and mental exhaustion caused by long term involvement in situations that are emotionally demanding.Although these definitions vary in several aspects, all of them share a view of burnout as a state of fatigue and emotional exhaustion that is the end result of gradual process of disillusionment $(6,7)$.

Studies revealed that teacher's job satisfaction and burnout is related to various aspects such as age, years of teaching and marital status. However, the results are controversial regarding the aspect of gender. For example, Sarıçam and Sakiz, reported significant differences between gender (8).

Another study showed that the burnout level of female teachers was significantly higher than their male counterparts (9) on the three factors of exhaustion (emotional exhaustion, reduced personal accomplishment and depersonalization). Relatively similar results were found in Sari, with the exception of depersonalization, which was found to be higher in males (10). Furthermore, young, single teachers exhibited increased levels of burnout (11-13). Finally, for Maslach, Schaufeli and Leiter burnout is also related to personality factors such as low self-esteem or passive coping strategies (14). Researches carried out in Greece showed that Greek teachers had moderate to low levels of job burnout $(11,15-23)$. Furthermore, Giannakidou examined factors leading to job burnout among teachers of the region of Xanthi, northern Greece (15). The research revealed that whereas primary school teachers had moderate levels of emotional exhaustion, teachers working in minority schools presented low levels of exhaustion.

Concerning Greek Physical Education [PE] teachers, the levels of burnout are relatively low (24). PE teachers from Greece appeared to be more satisfied with the job itself and the supervision, while they were dissatisfied with pay (7). A recent research has shown that PE teachers are characterized by moderate levels of burnout; however, the rate is higher compared to previous studies, indicating a rising trend (25). According to Ainscow and Tweddle and Blandford, teachers' job satisfaction and burnout can impact on their job performance and, influence on their social and cognitive development and, ultimately, their academic achievement (26-28). However, the issue of teachers' burnout and job satisfaction in Greek minority schools has received little research attention. Moreover, although studies attempted to investigate the relationship between job satisfaction and burnout within education, research within the context of physical education has received little attention. The researchers formulated this study in order to explore to what extent physical education teachers and teachers experienced burnout and job satisfaction in minority and public schools in the area of Thrace, northern Greece.

The purpose of this study was to examine the nature of job burnout and satisfaction among teachers and PE teachers of the minority schools of the region of Thrace (Evros, Rodopi, Xanthi), as compared to the levels of burnout and satisfaction experienced by teachers and PE teachers of public schools of the same region. The main objectives of the empirical part of this study were: 1) to explore the level of job satisfaction, 2) to investigate the level of teacher burnout amongst teachers and PE teachers of minority and public schools of Thrace and 3) to find out the relations between teachers' burnout and job satisfaction.

\section{MATERIAL AND METHODS}

Participants. The sample size employed for this study was consisted of 297 teachers and 142 PE teachers $($ Males $=192,43.5 \%$ and Females $=$ $248,56.5 \%$ ) serving at primary school levels in the regions of Evros, Rodopi and Xanthi. About $42 \%$ of the teachers served at minority schools, while 58\% served at public ones. Forth teen participants did not respond. The vast majority $(95 \%)$ of the sample hold a permanent job. The mean age for teachers was 46 years. The career background for teachers reported to be 17 years.

Measurements. The Employee Satisfaction Inventory (ESI) was used to assess P.E. teacher's job satisfaction (29). ESI consists of 24 items, which measures six dimensions of a job: the work itself 
(four items, e.g., my job is boring), pay (four items, e.g., paid less than I deserve), promotion (three items e.g., my perspective for promotiondevelopment is very limited), supervision (four items, e.g., my supervisor is rude), working conditions (five items, e.g., dangerous for my health) and organization as a whole (four items, e.g., the best school/institution I've ever worked). The internal consistencies (Cronbach's alpha) for each aspect were: for work itself (0.77), for pay (0.79), for promotion (0.62), for supervision (0.82), for working conditions (0.80) and for organization as a whole (0.76). Responses were given to a 5-point scale ranging from strongly agree (5) to strongly disagree (1). The educator's version of the Maslach Burnout Inventory (30), which has been modified and validated for the Greek population $(19,31)$, was used to measure job burnout. The inventory consists of twenty two items which measure the three dimensions of burnout: emotional exhaustion (nine items, e.g., at the end of the school day I feel exhausted) which describes feelings of being emotionally overextended and exhausted by work, depersonalization (five items, e.g., I feel disappointed by my job) which describes a cynical attitude and impersonal response between oneself and service recipients, and personal accomplishment (eight items, e.g., I've achieved many worthy things in my job) which describes feelings of efficacy and achievement in one's work with people. The internal consistencies (Cronbach's alpha) for each aspect were: for emotional exhaustion (0.81), for depersonalization $(0.60)$ and for personal accomplishment (0.86). For emotional exhaustion and depersonalization, high mean scores represent higher levels of burnout, whereas for personal accomplishment, low mean scores represent higher levels of burnout. Responses were given to a 7-point Likert scale ranging from never [0] to every day [6].

Design and Procedure. A questionnaire survey (anonymous questionnaires) has been carried out to investigate the interrelationships between burnout and job satisfaction. Paper and pencil questionnaires were distributed among the study sample and picked up by the researcher. The participants filled out a questionnaire which included three parts. Part one was a demographic and general condition information section. Part two was a job stress questionnaire while part three involved assessment of job burnout. The study was conducted between February and May 2016. Within this time period, there were not any significant socioeconomic changes with the exception of the new salary scale for public servants (Law 4354/15). Due to the demographic characteristics of the region of Thrace, the results of the study cannot be generalized to a large population. Findings can however be transferable to a future research

Data Analysis. There were six independent variables in the present study: teacher specialty, type of school, locale, sex, marital status and seniority. Nine factors were used: six from the ESI and three from the MBI questionnaire. Cronbach's alpha was used to assess the internal consistency of subscales. Pearson correlation analysis was used to examine the multivariate relationship between job satisfaction and burnout. MANOVA's and ANOVA's were used to investigate possible differences between the subscales of independent variables. SPSS 18 was used for computing all the above calculations. Significance level was set to 0.05 .

\section{RESULTS}

In Table 1 the Pearson correlation matrix, mean values, Standard Deviation and Cronbach's alpha rates, regarding job satisfaction and burnout of Physical Education teachers, are presented. The results confirmed the hypothesis that the two concepts would be correlated, since all the subscales of job satisfaction were negatively correlated with the main aspect of burnout, being emotional exhaustion. That means that when emotional exhaustion for Physical Education teacher's increases, their perceived job satisfaction decreases (and vice versa).

Table 1. Correlation Matrix, Descriptive Statistics Factors and Cronbach's Alpha of the ESI and MBI Subscales

\begin{tabular}{|c|c|c|c|c|c|c|c|c|c|}
\hline Subscales & 1 & 2 & 3 & 4 & 5 & 6 & 7 & 8 & 9 \\
\hline 1. Workingconditions & 1 & & & & & & & & \\
\hline 2.Pay & 0.050 & 1 & & & & & & & \\
\hline 3.Promotion & 0.037 & $0.205^{* *}$ & 1 & & & & & & \\
\hline 4.Work itself & $0.260^{* *}$ & -0.047 & 0.032 & 1 & & & & & \\
\hline 5. Supervision & $0.267^{* *}$ & 0.093 & 0.088 & $0.423^{* *}$ & 1 & & & & \\
\hline 6.Organization as a whole & $0.354^{* *}$ & 0.065 & 0.087 & $0.289^{* *}$ & $0.544^{* *}$ & 1 & & & \\
\hline 7.Emotional exhaustion & $-0.165^{* *}$ & -0.092 & $-0.102^{*}$ & $-0.364^{* *}$ & $-0.203^{* *}$ & $-0.152^{* *}$ & 1 & & \\
\hline 8. Personal accomplishment & -0.027 & $0.106^{*}$ & 0.084 & $-0.357^{* *}$ & $-.129^{* *}$ & $-0.145^{* *}$ & $0.451^{* *}$ & 1 & \\
\hline 9.Depersonalization & $0.147^{* *}$ & $-0.288^{* *}$ & 0.002 & $0.414^{* *}$ & $.098^{*}$ & 0.028 & $-0.162^{* *}$ & $-0.386^{* *}$ & 1 \\
\hline
\end{tabular}

**p <0.01 level; *p <0.05 level 
Specialty-related Differences. The results for the variables related to the teacher specialty, as well as the $\mathbf{p}$ level of importance are listed in Table 2.

With regard to job satisfaction, the results showed that there were significant differences due to specialty, F $(6,432)=17.10, \mathrm{p}<0.001$. Six ANOVA analyses were applied for each one of the factors related to job satisfaction. In the first analysis, the independent variable is teacher specialty while the dependent variable refers to the working conditions. In the second analysis, the dependent variable refers to the pay whereas in the third analysis the dependent variable is the promotion. In the fourth analysis, the dependent variable is the work itself and in the fifth analysis the dependent variable is the supervision. Finally, in the sixth analysis the dependent variable refers to the organization as a whole. The results indicated significant differences in 5 out of 6 dependent variables. More specifically, there were differences in the working conditions $\mathrm{F}$ $(1,437)=6.186, \mathrm{p}<0.05$, pay $\mathrm{F}(1,437)=15.940$, $\mathrm{p}<0.001$, promotion $\mathrm{F}(1,437)=27.498, \mathrm{p}<$ 0.001 , work itself $\mathrm{F}(1,437)=23.946, \mathrm{p}<0.001$ and supervision $\mathrm{F}(1,437)=20.130, \mathrm{p}<0.001$, whereas no significant difference was found in the variable 'organization as a whole.'

Moreover, PE teachers scored higher than teachers on all the dependent variables of the ESI questionnaire with the exception of the variable 'pay.' With regard to job burnout, the findings revealed statistically significant differences in relation to specialty, $\mathrm{F}(3,435)=14.80, \mathrm{p}<0.001$. In the following analysis of variance (ANOVA's), statistically significant differences were revealed between 'specialty' and the dependent variables 'emotional exhaustion' and 'personal accomplishment' $[\mathrm{F}(1,437)=17.66, \mathrm{p}<$ 0.001 and $F(1,437)=24.71, p<0.001$ relatively $]$. By contrast, no significant differences for burnout were found in relation to 'depersonalization.'

The factor 'specialty' is related to the variables of emotional exhaustion and personal accomplishment. In other words, PE teachers were more satisfied than teachers. Furthermore, the findings revealed that PE teachers had lowers scores in all the subscales of the ESI questionnaire.

Differences due to School Type. In Table 3 the means, the Standard Deviation, as well as the p level of the ESI and MBI subscales for the school type (minority/public) are presented.
With regard to job satisfaction, the results showed statistically significant differences for school type, $F(6.432)=3.29, p<0.01$. In the separate analysis of variance (ANOVA's) that followed, statistically significant differences were found for the 'working conditions' $F$ $(1,437)=15.41, \mathrm{p}<0.00$. No significant differences were revealed for the variables 'pay', 'promotion', 'work itself,' 'supervision' and 'organization as a whole'. The factor 'school type' seems to be related to the working conditions, as teachers working in minority schools seemed to be less satisfied than teachers working in public schools. With regard to burnout, no statistically significant differences were found for school type. The school type did not affect the subscales of burnout, as no statistically significant differences were found.

\section{DISCUSSION}

The purpose of the study was to investigate the relationship between job satisfaction and burnout and to evaluate differences in job satisfaction and burnout among teachers and P.E. teachers working in public and minority schools in the region of Thrace, Greece. It was hypothesized that P.E. teachers and teachers who work in primary schools will have different job satisfaction and burnout levels than those who work in minority schools. The second hypothesis was that job satisfaction dimensions of P.E. teachers will have a negative correlation with their burnout dimensions. The results revealed that when job satisfaction increases, the perceived burnout decreases. These results seem to agree with results from other studies, where job satisfaction and burnout presented medium to high negative correlation (16-23, 32). Parameters which could possibly affect teachers' job satisfaction is the existence of strong and consistent social bonds in Greece (32). Furthermore, the dimensions of teaching as permanent job and the lack of any official assessment also play a significant role in the low levels of burnout (21). Teacher's evaluation and school self-evaluation, which will be implemented in 2019, could possible affect teachers' levels of job satisfaction and burnout.

In the present study, the five dimensions of job satisfaction were negatively correlated with burnout, except for the dimension of pay. The results showed that when the rates of emotional exhaustion increase, the rates of job satisfaction decrease. These results agree with other studies, 
where job satisfaction and burnout showed medium to high negative correlation (33-35). Moreover, the dimensions of burnout related to the work itself and the supervision are negatively related to the main aspects of burnout, which are emotional exhaustion and depersonalization. On the contrary, they are positively related to the aspect of lack of personal accomplishment. This means that teachers with low levels of personal achievements presented high rates of job satisfaction.

Table 2. Means of the ESI Subscales for Specialty

\begin{tabular}{|lccccc|}
\hline & \multicolumn{2}{c}{ Teachers of Public Sector N(297) } & Physical Education Teachers N(142) & Sig. \\
& $\mathbf{M}$ & SD & M & SD & p \\
Job satisfaction factors & & & & & \\
Working conditions & $3.54^{*}$ & 0.728 & $3.73^{*}$ & 0.709 & 0.013 \\
Pay & $2.27^{*}$ & 0.839 & $1.92^{*}$ & 0.920 & 0.000 \\
Promotion & $2.42^{*}$ & 0.692 & $2.80^{*}$ & 0.711 & 0.000 \\
Work itself & $4.16^{*}$ & 0.531 & $4.44^{*}$ & 0.596 & 0.000 \\
Supervision & $3.90^{*}$ & 0.859 & $4.27^{*}$ & 0.719 & 0.000 \\
Organization as a whole & 3.30 & 0.780 & 3.39 & 0.956 & 0.267 \\
Burnout factors & & & & & \\
Emotional exhaustion & $22.08^{*}$ & 10.926 & $17.60^{*}$ & 9.413 & 0.000 \\
Personal accomplishment & $38.89^{*}$ & 6.578 & $42.04^{*}$ & 5.309 & 0.000 \\
Depersonalization & 3.33 & 4.106 & 2.85 & 3.361 & 0.225 \\
\hline
\end{tabular}

Table 3. Means of the ESI Subscales for School Type

\begin{tabular}{|lccccc|}
\hline & \multicolumn{2}{c}{ Minority School N(186) } & Public-school N(253) & SD \\
& $\mathbf{M}$ & SD & M & SD & p \\
Job Satisfaction Factors & & & & & \\
Working conditions & $3.45^{*}$ & 0.772 & $3.72^{*}$ & 0.670 & 0.000 \\
Pay & 2.08 & 0.850 & 2.21 & 0.900 & 0.111 \\
Promotion & 2.49 & 0.836 & 2.58 & 0.619 & 0.181 \\
Work itself & 4.24 & 0.537 & 4.26 & 0.589 & 0.624 \\
$\quad$ Supervision & 3.93 & 0.923 & 4.09 & 0.757 & 0.050 \\
$\quad$ Organization as a whole & 3.25 & 0.814 & 3.38 & 0.858 & 0.103 \\
Burnout Factors & & & & & \\
$\quad$ Emotional exhaustion & 20.20 & 10.745 & 20.95 & 10.605 & 0.465 \\
Personal accomplishment & 39.60 & 6.621 & 40.14 & 6.170 & 0.379 \\
Depersonalization & 3.22 & 4.110 & 3.14 & 3.715 & 0.838 \\
\hline
\end{tabular}

Note: * = statistically different, $\mathbf{p}<0.05$

It is also noteworthy that the results showed a significant relationship between job satisfaction and its components with improvement of performance and its components (36). Thus, the low rates of burnout are related to the high levels of job satisfaction. Other studies suggest that job satisfaction is correlated with two aspects of burnout; emotional exhaustion and lack of personal accomplishment (37). Regarding teacher specialty, the findings showed significant differences in all dimensions, except for the organization itself. P.E. teachers had higher rates in all the subscales of the ESI questionnaire concerning job satisfaction, with the exception of pay. A core finding of this study is that PE teachers experienced lower levels of burnout than teachers. On the contrary, no significant differences were found in the dimension of depersonalization.

Regarding the aspect of pay, the results of the present study differ from the study of Antoniou, Kourtesis, Koustelios and
Papaioannou, which found that P.E. teachers were more satisfied by their salary than their teacher colleagues (38). Additionally, P.E. teachers were more satisfied by the organization itself than other specialties. There are also studies that supported that teachers were satisfied with work itself and supervision. On the contrary, they were dissatisfied with pay and promotion (39).

It is also stressed that the subject of Physical Education is not considered as of high importance, leading to the production of lowered expectations (40, 41). Moreover, Physical education is a subject that, by its nature, depends on proper equipment and facilities. Given that, P.E. teachers exhibit high rates of independence and low levels of burnout (7). These results are in accordance with other studies (18).

The fact that of Physical Education teachers are more satisfied by their job than their colleagues is also related to the subject itself; Physical education is a subject which, by its 
nature, is not stressful. Another variable is the class atmosphere, which, according to other relative studies is correlated with teacher's professional development and with student's sociopsychological development (42-44).

Furthermore, there are significant correlations among factors related to satisfaction. According to the results, working conditions are correlated with the organization as a whole, the supervision and the work itself. Moreover, the work itself is correlated with the supervision, the organization as a whole and the working conditions. On the other hand, the supervisor is positively related to the organization as a whole. Results have revealed that the supervisor affects the teacher's attitude towards school and the profession itself. Teacher's stress is affected by factors such as limited state support, absence of training programs, poor infrastructure, parents' demands, affecting, thus, the levels of job satisfaction. Future studies could investigate whether the fact that Greek Physical Education teachers usually serve in more than one schools could also affect the rates of job satisfaction (45). This parameter was not investigated in the present study; however, it is an interesting issue for future studies.

Moreover, as a school subject, Physical Education differs from other subjects. The differences have to do with the working conditions of PE teachers (class structure, different expectations), as compared to other specialties. This is a factor which necessitates the investigation of the levels of job satisfaction and burnout among various teacher specialties.

In closing, it must be taken into consideration the time when this study was held. Greece was going through some rough socioeconomic changes and especially in the public sector where some serious budget and wages cuts had been administered. According to the Greek Federation of State School Teachers of Secondary Education, Greek teachers are underpaid when compared to teachers in the European Union. This fact explains teacher's dissatisfaction with pay (46). Teachers showed high levels of dissatisfaction regarding promotion, a finding that has been confirmed by the study of Kroupis, Kourtessis, Kouli, Tzetzis, Derri and Mavrommatis (47). Pay, as well as promotion affect the levels of burnout and, thus, the state should improve working conditions $(27,48)$. Furthermore, in order for primary teachers to be more satisfied and less burned out, there should be a linkage between pay and age (48).

\section{CONCLUSION}

Further exploration could be attempted to delve deeply into other issues related to job satisfaction and burnout. Despite the fact that most of the findings of the study were confirmed, the limitations of the present study should be kept in mind when interpreting the results. Firstly, it should be noted that since the sample consisted of Physical Education teachers and teachers from a specific region only, that prohibits generalizing the findings to other Physical Education teachers and teachers. A logical next step would be to apply a safer method of sampling, a method which will take into consideration the whole community of education.

Secondly, it should be taken into consideration the bilingual education received by children in the area of Thrace; the bilingual curriculum of minority schools. A third limitation concerns the diverse cultures of the region; the different religious beliefs; the support that children receive; their educational autonomy. Investigating and comparatively assessing the above factors is suggested to be a safer way for drawing safer conclusions. Despite these limitations, the results have given new insights that deserve further attention.

The above findings confirm the complexity of terms such as job burnout and satisfaction. Therefore, future research should help the organization/state by examining the ways in which the latter could help provide professional support and prevent employee burnout. This could be done through the conduction of personal interview surveys in which factors affecting job burnout and satisfaction will be investigated.

\section{APPLICABLE REMARKS}

- The education policy for minority schools teachers should focus on the development of skills for various aspects of the educational process, due to the teacher's multidimensional role.

- It is suggested that teachers working in minority schools should achieve their potential and develop considerable skills for classroom management.

- They need to be trained on how to react and how to deal with situations related to the social environment of the area of Thrace; they should develop skills for 
dealing with issues related to the student's different mother tongue and religious beliefs and for cooperating with parents.

- Both teachers and PE teachers working in minority schools need to be trained on how to work in single-post and multi-post schools.

- Supporting teachers by providing them with feedback is considered as a necessary condition so as for the job stress to be decreased and the satisfaction to be increased.

\section{REFERENCES}

1. Aziri B. Job Satisfaction: A Literature Review. Manage Res Pract. 2011;3(4):77-86.

2. Terason S. The Effect of Conflict Management in Thai Public-Sector Sport Organizations on Employee Job Satisfaction and Perceived Organizational Performance. Acad Strateg Manage J. 2018;17(1):168-172.

3. Wu G, Duan K, Zuo J, Yang J, Wen S. System Dynamics Model and Simulation of Employee WorkFamily Conflict in the Construction Industry. Int J Environ Res Public Health. 2016;13(11). doi: 10.3390/ijerph13111059 pmid: 27801857

4. Blandford S. Managing professional development in schools. London: Routledge; 2000.

5. Maslach C, Jackson SE. The measurement of experienced burnout. J Organ Behav. 1981;2(2):99113. doi: 10.1002/job.4030020205

6. Pines AM, Aronson E. Burnout: From Tedium to Personal Growth. New York: Free Press; 1981.

7. Koustelios A, Tsigilis N. The relationship between burnout and job satisfaction among physical education teachers: a multivariate approach. Europ Physic Edu Rev. 2016;11(2):189-203. doi: 10.1177/1356336x05052896

8. Sarıçam H, Sakız H. Burnout and teacher self-efficacy among teachers working in special education institutions in Turkey. Edu Stud. 2014;40(4):423-437. doi: 10.1080/03055698.2014.930340

9. Koustelios AD. Personal characteristics and job satisfaction of Greek teachers. Int J Edu Manag. 2001;15(7):354-358. doi: 10.1108/eum0000000005931

10. Sari H. An analysis of burnout and job satisfaction among Turkish special school headteachers and teachers, and the factors effecting their burnout and job satisfaction. Edu Stud. 2010;30(3):291-306. doi: 10.1080/0305569042000224233

11.Aventisian-Pagoropoulou A, Koubias E, Giavrimis P. [Burnout syndrome: Teacher's chronic stress and its transformation into job burnout]: Mentoras; 2002 [cited 2019]. Available from: http://www.pischools.gr/publications/mentor.

12.Kantas A. Job burnout among Greek. Arethas: Scientific Annual Report, Department of Primary Education: University of Patras; 1998 [cited 2019]. Available from: http://www.elemedu.upatras.gr/index.php/\%CF\%84\%CE\%BC\%CE\%AE\%CE\%BC\%CE\%B1/\%C $\mathrm{E} \% \mathrm{~B} 1 \% \mathrm{CF} \% 81 \% \mathrm{CE} \% \mathrm{AD} \% \mathrm{CE} \% \mathrm{~B} 8 \% \mathrm{CE} \% \mathrm{~B} 1 \% \mathrm{CF} \% 82$.

13. Mearns J, Cain JE. Relationships between Teachers' Occupational Stress and Their Burnout and Distress: Roles of Coping and Negative Mood Regulation Expectancies. Anxiety Stres Coping. 2003;16(1):71-82. doi: 10.1080/1061580021000057040

14. Maslach C, Schaufeli WB, Leiter MP. Job burnout. Annu Rev Psychol. 2001;52:397-422. doi: 10.1146/annurev.psych.52.1.397 pmid: 11148311

15. Giannakidou X. Job burnout, sources of job stress and self-efficacy in primary school teachers: PostGraduate Program in School-Evolutionary Psychology, Department of Psychology; 2014.

16. Daniilidou A. [Studying Primary School Teacher Burnout via three alternative models: Maslach model, Pines model and Copenhagen model] 2013.

17. Kantas A. Burnout syndrome among teachers and health professionals. Psychology. 1996;2(1):7185.

18. Kantas A, Vassilaki E. Burnout in Greek teachers: Main findings and validity of the Maslach Burnout Inventory. Work \& Stress. 1997;11(1):94-100. doi: 10.1080/02678379708256826

19. Kouli O, Kourtessis T, Tzetzis G, Karkaletsi F, Skordilis E, Bonti E. Job Satisfaction and Burnout of Greek Secondary Special Education Teachers. J Physic Act Nutrd Rehab. 2015;15:11-12.

20.Papastylianou A, Kaila M, Polychronopoulos M. Teachers' burnout, depression, role ambiguity and conflict. Soc Psycho Edu. 2009;12(3):295-314. 
21.Platsidou M, Agaliotis I. Burnout, Job Satisfaction and Instructional Assignment-related Sources of Stress in Greek Special Education Teachers. Int J Disabil Dev Edu. 2008;55(1):61-76. doi: 10.1080/10349120701654613

22. Stagia D, Iordanidis Y. Occupational stress and professional burnout among Greek teachers in secondary schools under conditions of economic crisis. Scientific Annual Report, Department of PreSchool Education, 2014 2241-200X

$1108-4634$.

23. Charalambous E. Sources of job stress and job burnout among secondary school teachers in the region of Attica. Athens: Charokopion University; 2012.

24.Tsigilis N, Zournatzi E, Koustelios A. Burnout among physical education teachers in primary and secondary schools. Int J Human Soc Sci. 2011;1(7):53-58.

25. Kroupis E. The effect of sports infrastructure in job satisfaction and burnout among Greek P.E. teachers of private and public schools 2012.

26. Ainscow M, Tweddle DA. Encouraging classroom success. London: David Fulton; 1988.

27. Grundy W, Blandford S. Developing a Culture for Positive Behaviour Management. Emotion Behav Difficult. 1999;4(3):5-9. doi: 10.1080/1363275990040302

28. Blandford S. Managing discipline in schools. London: Routledge; 1999.

29. Koustelios AD, Bagiatis K. The Employee Satisfaction Inventory (ESI): Development of a Scale to Measure Satisfaction of Greek Employees. Edu Psychol Meas. 2016;57(3):469-476. doi: 10.1177/0013164497057003008

30. Maslach C, Jackson SE. Maslach burnout inventory manual. 2nd ed. Palo Alto, CA: Consulting Psychologists Press; 1986.

31. Kokkinos CM. Factor structure and psychometric properties of the Maslach Burnout InventoryEducators Survey among elementary and secondary school teachers in Cyprus. Stress Health. 2006;22(1):25-33. doi: 10.1002/smi.1079

32.Papastylianou A, Kaila M, Polychronopoulos M. Teachers' burnout, depression, role ambiguity and conflict. Soc Psychol Edu. 2009;12(3):295-314. doi: 10.1007/s11218-008-9086-7

33. Bhana A, Haffejee N. Relation among measures of burnout, job satisfaction, and role dynamics for a sample of South African child-care social workers. Psychol Rep. 1996;79(2):431-434. doi: 10.2466/pr0.1996.79.2.431 pmid: 8909064

34. Dolan N. The relationship between burnout and job satisfaction in nurses. J Adv Nurs. 1987;12(1):312. doi: 10.1111/j.1365-2648.1987.tb01297.x pmid: 3643938

35. Koeske GF, Kirk SA, Koeske RD, Rauktis MB. Measuring the Monday blues: validation of a job satisfaction scale for the human services. Soc Work Res. 1994;18(1):27-35. doi: 10.1093/swr/18.1.27 pmid: 10134784

36. Kolbadinejad M, Ashraf Ganjouei F, Haji Anzehaei Z. Performance Evaluation Model according to Performance Improvement and Satisfaction of the Staff in the Individual Sports Federations and Federations with Historical Aspect. Annal Appl Sport Sci. 2018;6(4):59-67. doi: 10.29252/aassjournal.6.4.59

37. Skaalvik EM, Skaalvik S. Does school context matter? Relations with teacher burnout and job satisfaction. Teach Teach Edu. 2009;25(3):518-524. doi: 10.1016/j.tate.2008.12.006

38. Antoniou X, Kourtessis T, Koustelios A, Papaioannou A. Job satisfaction among Physical Education Teachers compared to teachers of other specialties. Sport Soc. 2007;45:76-82.

39. Koustelios A, Kousteliou I. Relations among Measures of Job Satisfaction, Role Conflict, and Role Ambiguity for a Sample of Greek Teachers. Psychol Rep. 2016;82(1):131-136. doi: 10.2466/pr0.1998.82.1.131

40.Fejgin N, Ephraty N, Ben-Sira D. Work Environment and Burnout of Physical Education Teachers. J Teach Physic Edu. 1995;15(1):64-78. doi: 10.1123/jtpe.15.1.64

41.Smith D, Leng GW. Prevalence and Sources of Burnout in Singapore Secondary School Physical Education Teachers. J Teach Physic Edu. 2003;22(2):203-218. doi: 10.1123/jtpe.22.2.203

42. Voulgaris S, Matsaggouras E, editors. The psychological climate of the primary school classroom. 5th Panhellenic conference; 2004; Athens: Education and Teaching in the society of knowledge. 
43. Thapa A, Cohen J, Guffey S, Higgins-D’Alessandro A. A Review of School Climate Research. Rev Edu Res. 2013;83(3):357-385. doi: 10.3102/0034654313483907

44. Travers CJ, Cooper CL. Teachers Under Pressure: Stress in the Teaching Profession. London: Routledge; 1996.

45. Greek Federation of Secondary Education State School Teachers (OLME). A study on Education and Teachers in Greece, Europe and other countries 2012 [cited 2015]. Available from: http://olmeattik.att.sch.gr.

46. Kroupis I, Kourtessis T, Kouli O, Tzetzis G, Derri V, Mavrommatis G. Job satisfaction and burnout among Greek P.E. teachers. A comparison of educational sectors, level and gender. Cultura Ciencia Deporte. 2017;12(34):5-14. doi: 10.12800/ccd.v12i34.827

47. Tye BB, O'Brien L. Why are Experienced Teachers Leaving the Profession? Phi Delta Kappan. 2016;84(1):24-32. doi: 10.1177/003172170208400108

48. Vedder R, Hall J. Private school competition and public school teacher salaries. J Labor Res. 2000;21(1):161-168. doi: 10.1007/s12122-000-1010-7 